\title{
Hemorrhage complicating the course of severe acute pancreatitis
}

\author{
Vikas Gupta ${ }^{1}$, Pradeep Krishna ${ }^{1}$, Rakesh Kochhar ${ }^{2}$, Thakur Deen Yadav ${ }^{1}$, \\ Venu Bargav ${ }^{1}$, Asheesh Bhalla ${ }^{3}$, Naveen Kalra ${ }^{4}$, and Jai Dev Wig ${ }^{1}$ \\ Departments of ${ }^{1}$ General Surgery, ${ }^{2}$ Gastroenterology, ${ }^{3}$ Internal Medicine, and ${ }^{4}$ Radiodiagnosis, \\ Postgraduate Institute of Medical Education and Research, Chandigarh, India
}

\begin{abstract}
Backgrounds/Aims: The course of severe acute pancreatitis (SAP) complicated by hemorrhage is associated with poor outcome. Methods: Twenty-four (13\%) out of 183 cases of SAP had hemorrhagic complications- 12 intraabdominal \& 12 intraluminal, 13 had major \& 11 had minor and 16 had de-novo \& 8 post-surgical bleeding. The mean duration of pancreatitis prior to bleeding was $27 \pm 27.2$ days. Results: Predictors of haemorrhage on univariate analysis were delayed admission (0.037), more than one organ failure $(p=0.008)$, presence of venous thrombosis $(p=0.033)$, infective necrosis $(0.001)$ and systemic sepsis - bacterial $(0.037) \&$ fungal $(p=0.032)$. On multivariate analysis infected necrosis $(\mathrm{OR}=11.82)$ and presence of fungal sepsis $(\mathrm{OR}=3.73)$ were the significant factors. Patients presenting with more than one organ failure and bacterial sepsis had borderline significance on multivariate analysis. Need for surgery $(50 \%$ vs. $12.6 \%)$, intensive care stay $(7.4 \pm 7.9$ vs. $5.4 \pm 5.2$ days) and mortality $(41.7 \%$ vs. $10.7 \%)$ were significantly higher in patients who suffered haemorrhage. Seven of the 13 with major bleeding had pseudoaneurysms- 4 were embolized, 4 needed surgery including 1 embolization failure. Seven with intraabdominal bleeding required surgical intervention, 2 had successful embolization and 3 had expectant management. CT severity index and surgical intervention, were significantly associated with intraabdominal bleeding. Organ failure, presence of pseudoaneurysm and surgical intervention were associated with major bleeding. Conclusions: Hemorrhage in SAP was associated with increased morbidity and mortality. Infected necrosis accentuated the degradation of the vessel wall, which predispose to hemorrhage. Luminal bleeding may be indicative of erosion into the adjacent viscera by the pseudoaneurysm. (Ann Hepatobiliary Pancreat Surg 2020;24:292-300)
\end{abstract}

Key Words: Haemorrhage; Pancreatitis; Bleeding; Complication; Acute; Abdominal; Pseudoaneurysm

\section{INTRODUCTION}

Severe Acute pancreatitis (SAP) carries a mortality of $15-20 \%{ }^{1-3}$ Although gastrointestinal (GI) bleed is not considered as organ failure in the revised Atlanta classification, ${ }^{4}$ still the consequences associated with it can sometimes be detrimental. Due to the rarity of this complication, there has been a lot of variability in its reporting. The reported incidence is $1-23 \% .^{5-9}$ However, whenever this complication is encountered, it can be fatal in onethird to half of the cases. ${ }^{5-7}$ Haemorrhage in the peripancreatic area further complicates the course of necrosis and increases mortality. ${ }^{5-9}$ Haemorrhage can arise secondary to erosion of the vascular wall, formation of pseudoaneurysms or microvascular ischaemic complications, spleno-porto-mesenteric venous thrombosis causing oesophagogastric varices ${ }^{5,6}$ and following surgical debridement. $^{5,10-12}$ Severe inflammation and activated enzymes which leak into the retroperitoneum in SAP can digest the viscus and vascular structure, including the relatively resistant arterial wall. This leads to acute erosion, disruption, or wall weakening and pseudoaneurysm formation which might eventually rupture and bleed. ${ }^{5,6,8,10,12}$ Pancreatic necrosis, abscess and pseudocysts may produce similar damage to the vasculature. In addition to pancreatic debridement, timing of surgery and surgical technique have also been identified as risk factors for the occurrence of haemorrhage. ${ }^{5,8,10,12}$

There is paucity of literature on the haemorrhagic complications arising as a result acute pancreatitis, so the

Received: October 2, 2019; Revised: April 3, 2020; Accepted: April 9, 2020

Corresponding author: Vikas Gupta

Department of General Surgery, Postgraduate Institute of Medical Education and Research, Sector 12, Chandigarh 160012, India Tel: +91-172-2756645, Fax: +91-172-2744401, E-mail: vikaspgi@gmail.com

Copyright (C) 2020 by The Korean Association of Hepato-Biliary-Pancreatic Surgery

This is an Open Access article distributed under the terms of the Creative Commons Attribution Non-Commercial License (http://creativecommons.org/ licenses/by-nc/4.0) which permits unrestricted non-commercial use, distribution, and reproduction in any medium, provided the original work is properly cited. Annals of Hepato-Biliary-Pancreatic Surgery • pISSN: 2508-5778 - eISSN: 2508-5859 
present study was planned to classify and assess the outcome of the course of severe acute pancreatitis complicated by haemorrhage.

\section{MATERIALS AND METHODS}

From January 2005 to December 2012, patients with acute pancreatitis were reviewed - prospectively (June 2011 to December 2012) and retrospectively (January 2005 to May 2011) - at Postgraduate Institute of Medical Education and Research, Chandigarh, a tertiary care hospital in India. The study was approved by the Institute ethics committee. Informed consent was taken from all the patients prior to enrolment in the prospective group. Acute pancreatitis was diagnosed by means of history, clinical examination, and radiological examination. The diagnosis of severe acute pancreatitis was established as per the revised Atlanta classification ${ }^{4}$ as the presence of persistent organ failure (organ failure lasting greater than 48 hours).

The patients were evaluated for demographic data, etiology, clinical presentations and radiological details. The patients with organ failure were given appropriate support. Periodic evaluation was performed with hematological, biochemical, microbiological and imaging parameters. Antibiotics were routinely used in all the patients. Nutrition was instituted once the patients were stabilized. Enteral route was preferred wherever possible. Patients deteriorating on conservative management were managed with radiological guided percutaneous catheter drainage. Surgical necrosectomy was reserved for patients not improving after percutaneous drainage. During the course of hospitalization the patients were closely observed for the development of haemorrhagic complications which were classified as below. Morbidity and mortality associated with haemorrhage occurring in pancreatitis was recorded.

\section{Classification of haemorrhage}

i) Site

a) Luminal as defined by the presence of hematemesis, melena or blood in nasogastric tube.

b) Extraluminal or Intraabdominal haemorrhage: blood emanating through drains placed percutaneously or at operation; or development of unexplained hemodynamic instability or CECT findings consistent with presence of contrast extravasation into the peripancreatic cyst, peri- toneal cavity or retroperitoneum.

ii) Timing

a) De novo: prior to surgical intervention during the course of illness.

b) Post-surgical: following surgical interventions.

iii) Severity

a) Major haemorrhage: as defined by an acute reduction in haemoglobin concentration of at least $2 \mathrm{~g} / \mathrm{dl}$ in a patient with overt bleeding and/or hemodynamic instability in an otherwise stable patient, in whom other causes of hemodynamic instability, such as septic shock or abdominal compartment syndrome, seemed unlikely.

b) Minor haemorrhage: not fitting into the category of major haemorrhage.

\section{Management protocol for haemorrhage (Fig. 1)}

Luminal haemorrhage was evaluated with endoscopy while patients with extraluminal and/or post operative bleeding as well as major luminal bleeding underwent computerized tomogram (CT) angiogram. Further management was governed by the ability to localize. Patients, in whom bleeding was localized, were managed either with embolization or surgery depending on the hemodynamic stability. Patients, in whom bleeding was not localized on CT angiogram were evaluated for severity.

All patients with severe bleeding not localized on CT angiogram were subjected to digital subtraction angiogram (DSA). Those with minor bleeding and not localized on CT angiogram were closely observed for recurrence of bleeding. In case of recurrent bleeding DSA was carried out.

\section{Statistical analysis}

Descriptive statistics were used. Data was expressed as mean \pm SD or mean (range) as appropriate. Mann Whitney U test was used to evaluate ordinal data like CTSI. Chi square test was used for analysis of nominal data. Factors which were found significant on univariate analysis were entered into multivariate logistic regression analysis. Statistical significance was set at $<0.05$.

\section{RESULTS}

A total of 183 patients of severe acute pancreatitis (SAP) were evaluated during the study period - 86 pro- 


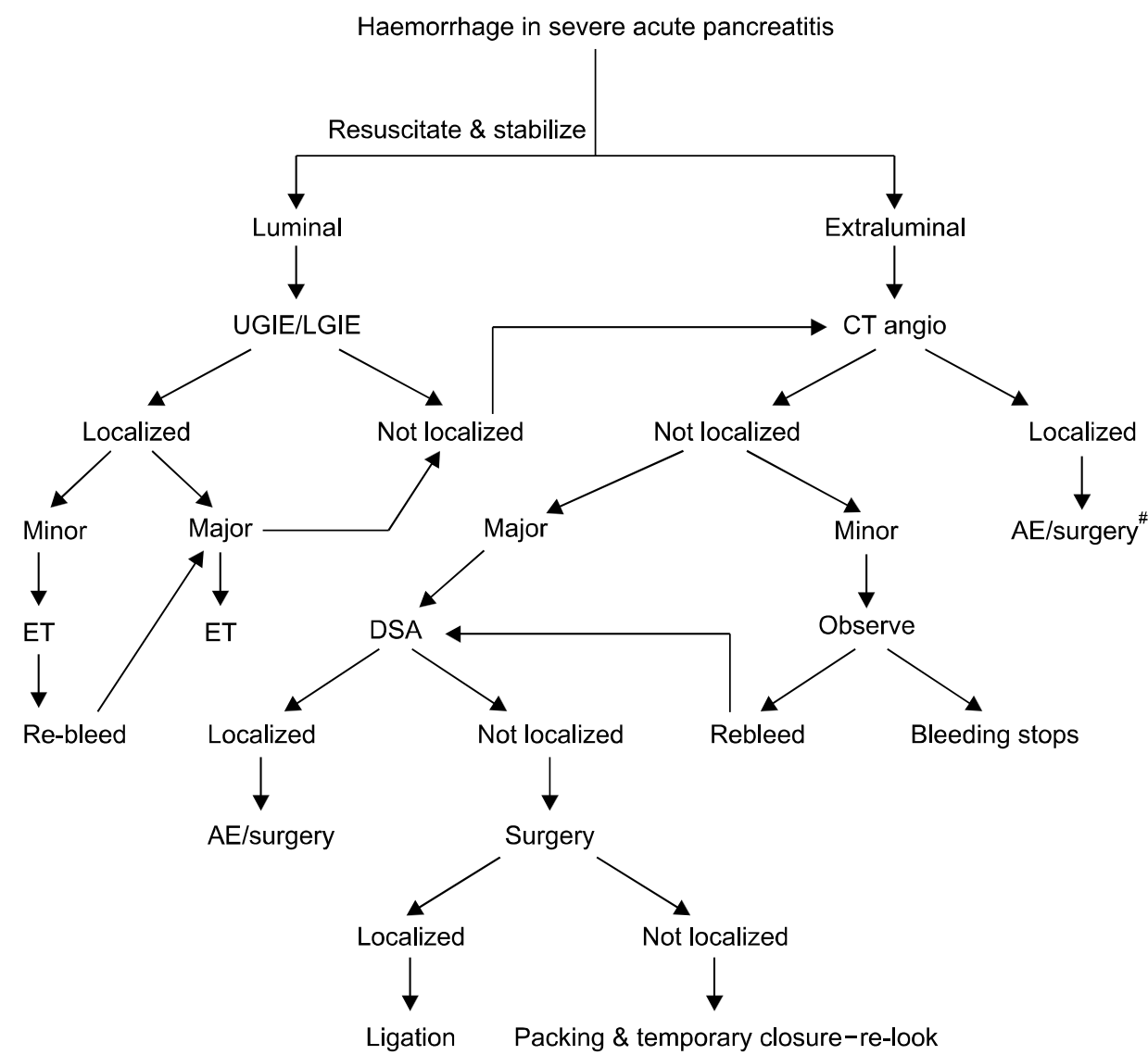

Fig. 1. Algorithm for management of patients experiencing haemorrhage during the course of acute pancreatitis. "Irrespective of the bleed being major or minor; UGIE, upper gastrointestinal endoscopy; LGIE, lower gastrointestinal endoscopy; CT angio, computed tomogram angiography; $\mathrm{ET}$, endoscopic therapy; AE, angioembolization; DSA, digital substraction angiography. spectively and 97 retrospectively. The mean age was $39.6 \pm 13.0$ years with a sex ratio of (M:F) 2.58:1. Etiology was alcohol in $92(49.7 \%)$ and biliary in 50 (27.3\%). Mean duration between the onset of symptoms and admission to a tertiary care facility was $12.51 \pm 17.09$ (1-31)

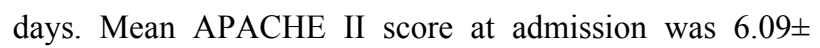
4.13 and mean CTSI was $8.45 \pm 1.47$. At presentation to our hospital, $88(48.09 \%)$ patients had organ failure. The mean number of organ failure at admission was 0.76 . However, during the course of hospitalization, all patients went on to develop organ failure. Infected pancreatic necrosis was seen in 47 (25.68\%), blood stream bacterial and fungal infections were observed in $45(24.59 \%)$ and $12(6.56 \%)$ respectively. Venous thrombosis was observed in $21(11.48 \%)$. Pseudoaneurysm of peripancreatic vasculature was seen in nine $(4.92 \%)$. Percutaneous drainage was required in $96(52.46 \%)$ patients. Surgical interventions were required in $32(17.49 \%)$ patients. Overall mortality rate was $14.75 \%$ (27). Mean ICU stay and hospital stay was $5.80+5.61$ days and $18.91+12.82$ days.

\section{Source \& localization}

Although, all luminal bleedings were localized by endoscopy, but those who had major bleeding were subjected for CT angiography in addition. Seven (58\%) had false luminal bleed arising as a result of - intraluminal rupture of pseudoaneurysm in 4 and spontaneous rupture of pancreatic collection into hollow viscus in 3 (Fig. 2). Haemorrhage associated with the former was massive, while the later was self limiting.

Extraluminal bleeding could not be localized in seven (58\%) patients.

CT angiogram was done in 16 patients showed pseudoaneurysm in 8 (7 ruptured) and diffuse contrast extravasation without getting localized in 1. Pseudoaneurysm involved splenic artery in 5 and one each of gastro-duodenal (without rupture), superior mesenteric and left gastric arteries.

\section{Management of haemorrhage}

\section{Luminal haemorrage}

Minor luminal bleeding with intraluminal source seen 


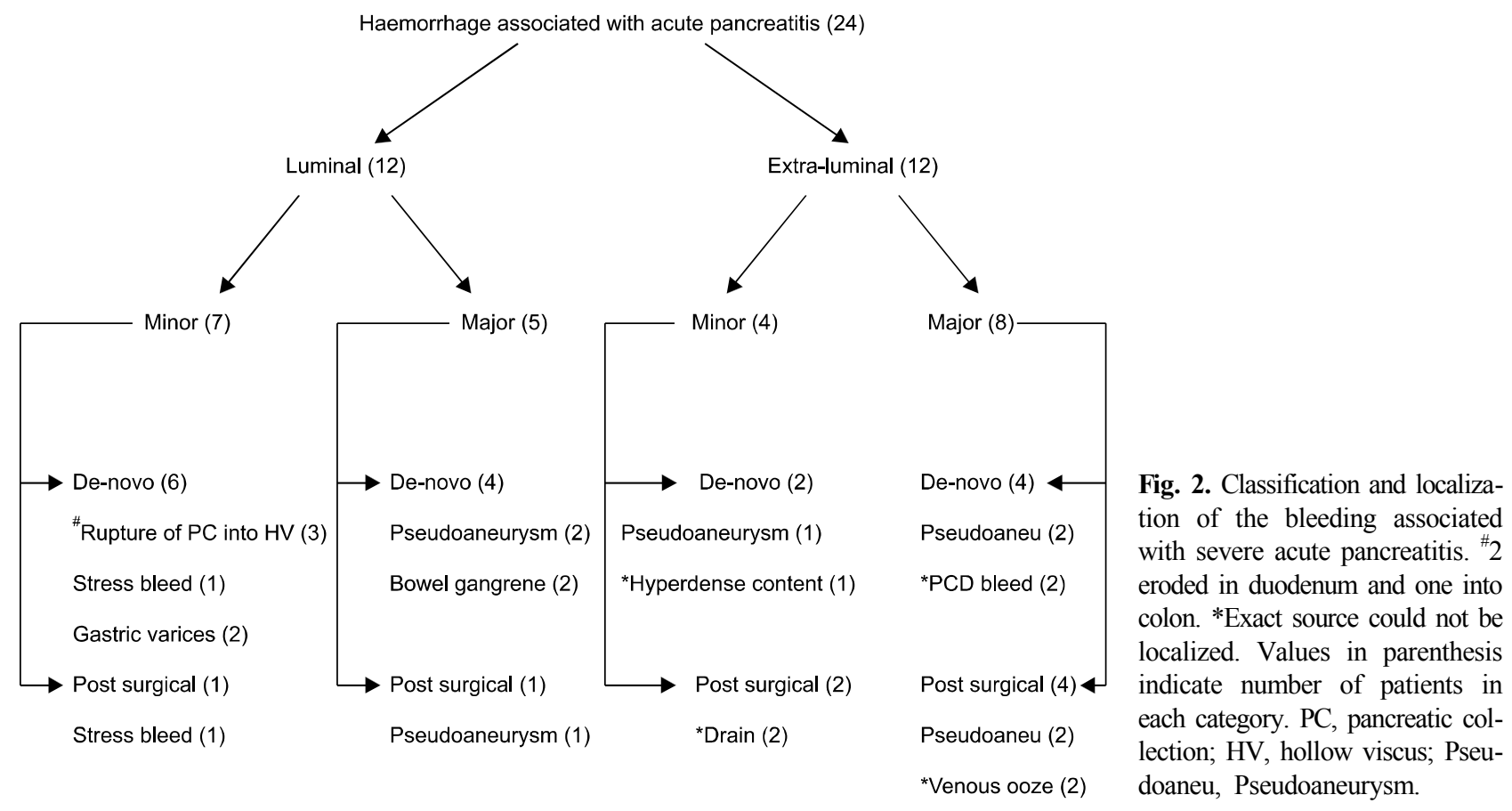

in three patients was managed by endoscopic therapy (sclero, heater probe and argon plasma coagulation). False luminal bleed due to rupture of pancreatic collection observed in three patients was self limiting and did not require any intervention for bleeding, however, two patient - one with duodenal rupture mandated surgery because of multiple duodenal perforations and worsening sepsis and another with colonic rupture needed surgery due to worsening sepsis.

Both cases of major luminal bleeding due to colon ischemia underwent colectomy (1 segmental \& 1 subtotal). Two of the three patients with pseudoaneurysm mandated surgical ligation and necrosectomy while one developed postoperative pseudoaneurysm was managed by DSA and embolization.

\section{De-novo haemorrhage}

Two cases of de-novo minor extraluminal bleeding were due to - pseudoaneurysm in one and hyerdense collection on CT in another. The former was managed by embolization and later had expectant management. Two patients with post-surgical with minor bleeding from drain were not localized on CT angiogram and were closely observed, however, both of them did not require any further intervention.

De-novo major extraluminal bleeding due to pseudoa- neurysms was seen in two patients, which was successfully embolized in one, however another had re-bleeding and required surgical intervention. Two patients with bleeding from PCD could not be localized on angiogram, and were operated upon. Both of them had venous ooze and underwent packing and temporary abdominal closure.

\section{Post surgical haemorrhage}

One of the two patients with pseudoaneurysms postsurgical necrosectomy had major extraluminal bleeding and was managed by surgical ligation while another one died of exsanguination before any intervention could be done. Other two with diffuse venous bleeding were managed by packing and temporary abdominal closure.

Overall, 12 patients were operated upon - control of haemorrhage in 8 and control of sepsis in 4 . Mortality in operated patients was significantly higher [7 (58\%) versus 2 (17\%), $p=0.044$, OR 6.39, CI 1.01-59.46] when compared to those not operated upon.

\section{Predictors of bleeding complications}

On univariate analysis delayed referral to a tertiary care facility, higher APACHE II score, more number of organ failure at admission, presence of venous thrombosis, presence of infective necrosis and occurrence of systemic sepsis during the course of illness were the predictors of 
bleeding complications (Table 1). On multivariate analysis presence of infected necrosis (OR 11.82) and presence of fungal sepsis (OR 3.73) were significant factors for te occurrence of haemorrhage. More number of organ failure at admission and presence of bacterial sepsis had borderline significance with haemorrhagic complications on multivariate analysis.

Occurrence of pseudoaneurysms, need for surgical intervention, intensive care stay and mortality were significantly higher on univariate and multivariate analysis in patients who had haemorrhage.

Luminal versus extraluminal (abdominal) bleed- ing: Patients with extraluminal bleeding had more severe pancreatitis and higher need for surgical intervention (Table 2). There was a trend towards delayed presentation of abdominal bleeding.

Major versus minor bleeding: patients with major bleeding had lesser mean number of organ failure, higher incidence of pseudoaneurysms, and a higher need for surgery (Table 3).

De-novo versus post-surgical bleed: Both the groups were comparable in terms of severity and need for interventions (Table 4).

Table 1. Comparative data between patients with and without haemorrhage

\begin{tabular}{|c|c|c|c|c|c|c|}
\hline Parameter & $\begin{array}{l}\text { Entire cohort } \\
\qquad(\mathrm{n}=183)\end{array}$ & $\begin{array}{c}\text { With } \\
\text { haemorrhage } \\
(n=24)\end{array}$ & $\begin{array}{c}\text { With-out } \\
\text { haemorrhage } \\
(n=159)\end{array}$ & $\begin{array}{l}\text { Univariate } \\
p \text {-value }\end{array}$ & $\begin{array}{c}\text { Multivariate } \\
p \text {-value }\end{array}$ & $\begin{array}{c}\text { OR }(95 \% \\
\text { confidence } \\
\text { interval })\end{array}$ \\
\hline Age (years) & $39.58 \pm 12.95$ & $\begin{array}{l}39.17 \pm 16.41 \\
\quad(15-90)\end{array}$ & $\begin{array}{l}39.64 \pm 12.44 \\
(13-70)\end{array}$ & 0.507 & & \\
\hline Sex ratio $(\mathrm{M}: \mathrm{F})$ & $2.58: 1$ & $3: 1$ & $2.5: 1$ & 0.416 & & \\
\hline Etiology & & & & 0.934 & & \\
\hline Alcohol & 92 & 14 & 78 & & & \\
\hline Biliary & 50 & 5 & 45 & & & \\
\hline Other & 41 & 5 & 36 & & & \\
\hline $\begin{array}{l}\text { Interval } \mathrm{b} / \mathrm{w} \text { onset } \\
\text { and admission* } \\
\text { (days) }\end{array}$ & $12.51 \pm 17.09$ & $24.0 \pm 30.28$ & $10.06 \pm 13.41$ & 0.037 & 0.792 & $\begin{array}{c}1.02 \\
(0,98-1.06)\end{array}$ \\
\hline Comorbidities & 28 & 1 & 27 & 0.584 & & \\
\hline APACHEII & $6.09 \pm 4.13$ & $6.9 \pm 5$ & $5.8 \pm 3.7$ & 0.022 & 0.367 & $\begin{array}{c}0.91 \\
(0.74-1.10)\end{array}$ \\
\hline $\begin{array}{l}\text { Mean number of } \\
\text { organs failure** }\end{array}$ & 0.76 & 1.125 & 0.70 & 0.008 & 0.064 & $\begin{array}{c}1.13 \\
(0.54-2.37)\end{array}$ \\
\hline Presence of collections & 85 & 14 & 71 & 0.417 & & \\
\hline Infected necrosis & 47 & 14 & 33 & 0.000 & 0.00 & $\begin{array}{c}11.82 \\
(2.40-58.29)\end{array}$ \\
\hline Bacterial sepsis & 45 & 10 & 35 & 0.037 & 0.08 & $\begin{array}{c}2.15 \\
(0.37-12.64)\end{array}$ \\
\hline Fungal sepsis & 12 & 4 & 8 & 0.032 & 0.03 & $\begin{array}{c}3.73 \\
(1.03-13.50)\end{array}$ \\
\hline Venous thrombosis & 21 & 5 & 16 & 0.12 & & \\
\hline CTA pseudoaneurysm & 9 & 8 & 1 & 0.000 & 0.00 & $\begin{array}{c}113 \\
(7.01-1801)\end{array}$ \\
\hline Need for PCD & 96 & 11 & 85 & 0.485 & & \\
\hline $\begin{array}{l}\text { Need for } \\
\text { surgical intervention }\end{array}$ & 32 & 12 & 20 & 0.000 & 0.058 & $\begin{array}{c}2.50 \\
(0.55-11.28)\end{array}$ \\
\hline Mortality & 27 & 10 & 17 & 0.000 & 0.014 & $\begin{array}{c}5.72 \\
(0.94-34.95)\end{array}$ \\
\hline ICU stay & $5.80+5.61$ & $7.35+7.93$ & $5.35+5.20$ & 0.000 & 0.481 & $\begin{array}{c}1.58 \\
(0.1-24.78)\end{array}$ \\
\hline Hospital stay & $18.91+12.82$ & $21.96+15.73$ & $18.48+12.7$ & 0.388 & & \\
\hline
\end{tabular}

*Admission to a tertiary care facility, **At admission

APACHE, acute physiology and chronic health evaluation; CTA, computed tomography angiogram; PCD, percutaneous drainage; ICU, intensive care unit 
Table 2. Comparison between those with luminal and abdominal haemorrhage

\begin{tabular}{lccc}
\hline \multicolumn{1}{c}{ Parameter } & $\begin{array}{c}\text { Luminal haemorrhage } \\
(\mathrm{n}=12)\end{array}$ & $\begin{array}{c}\text { Abdominal haemorrhage } \\
(\mathrm{n}=12)\end{array}$ & $p$-value \\
\hline Age & $38.83 \pm 12.48$ & $39.50 \pm 20.2$ & 0.923 \\
Sex ratio- M:F & $3: 1$ & $3: 1$ & 1.00 \\
Interval between onset and bleed* & $23.0 \pm 31.2$ & $31.8 \pm 20.9$ & 0.055 \\
APACHE II & $7.7 \pm 4.1$ & $7.6 \pm 6.7$ & 0.359 \\
CTSI & $8.5 \pm 1.16$ & $9.42 \pm 1.16$ & 0.046 \\
Mean number of organ failure** & 1.50 & 0.75 & 0.261 \\
Venous thrombosis & $3(25 \%)$ & $2(16.66 \%)$ & 0.384 \\
Pseudoaneurysm & $4(33.3 \%)$ & $4(33.3 \%)$ & 1.000 \\
Infected necrosis & 6 & 8 & 0.198 \\
Sepsis & 4 & 3 & 0.332 \\
Need for surgery & $3(25 \%)$ & $9(75 \%)$ & 0.041 \\
Mortality & $3(33.3 \%)$ & $6(50 \%)$ & 0.206 \\
Hospital stay & $23.42 \pm 18.44$ & $20.50 \pm 13.13$ & 0.954 \\
ICU stay & $7.38 \pm 3.58$ & $7.33 \pm 10$ & 0.174 \\
\hline
\end{tabular}

*Onset of pancreatitis, **At admission

APACHE, acute physiology and chronic health evaluation; CTSI, computed tomography severity index; ICU, intensive care unit

Table 3. Comparison between major and minor haemorrhage

\begin{tabular}{lccc}
\multicolumn{1}{c}{ Parameters } & $\begin{array}{c}\text { Major haemorrhage } \\
(\mathrm{n}=13)\end{array}$ & $\begin{array}{c}\text { Minor haemorrhage } \\
(\mathrm{n}=11)\end{array}$ & $p$-value \\
\hline Age & $41.54 \pm 17.34$ & $36.36 \pm 15.64$ & 0.455 \\
Sex ratio M:F & $1: 5.5$ & $1: 1.75$ & 0.163 \\
Interval between onset and bleed* & $34.54 \pm 32.02$ & $22.55 \pm 28$ & 0.359 \\
APACHE II & $8.27 \pm 5.2$ & $6.38 \pm 4.92$ & 0.381 \\
CTSI & $9.18 \pm 1.16$ & $8.77 \pm 1.30$ & 0.043 \\
Mean number of organ failure** & 1.69 & 0.62 & 0.243 \\
Venous thrombosis & $1(7.4 \%)$ & $4(36.3 \%)$ & 0.020 \\
Pseudoaneurysm & $7(53.8 \%)$ & $1(9.1 \%)$ & 1.000 \\
Infected necrosis & 7 & 6 & 0.691 \\
Sepsis & 4 & 2 & 0.041 \\
Need for surgery & $9(69.2)$ & $3(27.3)$ & 0.422 \\
Mortality & $6(46.2 \%)$ & $3(27.2 \%)$ & 0.685 \\
Hospital stay & $21.77 \pm 13.14$ & $22.18 \pm 19.03$ & 0.909 \\
ICU stay & $8.7 \pm 10.44$ & $6 \pm 4.37$ & \\
\hline
\end{tabular}

*Onset of pancreatitis, **At admission

APACHE, acute physiology and chronic health evaluation; CTSI, computed tomography severity index; ICU, intensive care unit

\section{DISCUSSION}

The present study has proposed the classification system for haemorrhage associated with acute pancreatitis. The need for intervention can be based on the algorithm developed as per the proposed classification. Although bleeding associated with pancreatitis should be addressed with aggressive management, but we observed a small subset of patients with non localized minor bleeding who could be managed expectantly. The intervention options for such patients are very limited due to the nature and non-localization. Another interesting group of patients we observed was the ones with rupture of pancreatic collection into the hollow viscus. These patients had minor intra-luminal bleed followed by clinical improvement of the symptoms. However, the need of further intervention if at all required was due to the infective complications arising as a result of contamination of the pancreatic collection by the GI tract or due to the development of GI fistulae.

Occurrence of haemorrhage during the course of acute 
Table 4. Comparision between de-novo and post surgical haemorrhage

\begin{tabular}{lccc}
\multicolumn{1}{c}{ Parameters } & $\begin{array}{c}\text { De-novo haemorrhage } \\
(\mathrm{n}=16)\end{array}$ & $\begin{array}{c}\text { Post-surgical haemorrhage } \\
(\mathrm{n}=8)\end{array}$ & $p$-value \\
\hline Age & $39.13 \pm 18.15$ & $39.25 \pm 13.47$ & 0.829 \\
Sex ratio M:F & $12: 4$ & $6: 2$ & 1.000 \\
Interval between onset and bleed* & $32.06 \pm 35.56$ & $23 \pm 15$ & 0.806 \\
APACHE II & $7.19 \pm 5.2$ & $7.38 \pm 4.95$ & 0.684 \\
CTSI & $8.88 \pm 1.14$ & $9.13 \pm 1.45$ & 0.467 \\
Mean number of organ failure** & $12(75 \%)$ & $3(37.5 \%)$ & 0.368 \\
Venous thrombosis & $4(25 \%)$ & $1(12.5 \%)$ & 0.603 \\
Pseudoaneurysm & 5 & 3 & 0.127 \\
Infected necrosis & 7 & 7 & 0.079 \\
Sepsis & 4 & 3 & 0.463 \\
Mortality & $4(25 \%)$ & $5(62.5 \%)$ & 0.159 \\
Hospital stay & $23.31 \pm 16.51$ & $19.25 \pm 14.70$ & 0.624 \\
ICU stay & $5.62 \pm 3.9$ & $10.57 \pm 12.2$ & 0.604 \\
\hline
\end{tabular}

*Onset of pancreatitis, **At admission

APACHE, acute physiology and chronic health evaluation; CTSI, computed tomography severity index; ICU, intensive care unit

pancreatitis is an ominous sign as it sharply increases the mortality. About one-third to half the patients experiencing haemorrhage die after this catastrophic complcation. ${ }^{5,6,9,12}$ There has been a lot of variability in reporting the incidence of haemorrhage associated with pancreatitis due to the rarity of this complication and varied presentations. ${ }^{5-12}$ Most of the large reports on pseudoaneurysms associated with pancreatitis include both acute and chronic cases. ${ }^{5,13-18}$ EPAMI (Epidemiología de la Pancreatitis Aguda en Medicina Intensiva) Study group has reported $11 \%$ incidence of abdominal haemorrhage in critically ill patients with pancreatitis across 46 intensive care units from Spain and Latin America. ${ }^{12}$ Wei at al. ${ }^{9}$ in a report from China reported $15 \%$ incidence of haemorrhage with acute necrotizing pancreatitis. Tang et al. ${ }^{19}$ encountered $11.5 \%$ incidence of haemorrhage a study of more than 500 patients of acute pancreatitis. However, the incidence of haemorrhage in severe and moderately severe pancreatitis was $17 \%$. In the present study we report $13 \%$ incidence of haemorrhage in severe acute pancreatitis.

The development of haemorrhage has been linked to disease severity of illness. ${ }^{7-9,12,19}$ We observed a higher mean number of organ failure in patients experiencing haemorrhage. Others have also observed higher severity scoring indices and organ failure associated with the occurrence of haemorrhage in acute pancreatitis. A recent study (MRI) reported $7.7 \%$ and $19.2 \%$ incidence of haemorrhage respectively in mild and severe pancreatitis as defined by APACHE II score. ${ }^{19}$ Labarca et al. ${ }^{12}$ in addition observed increasing age and gall stone etiology as the risk factors on multivariate analysis. On the contrary, another large study found preoperative sepsis as a risk factor on multivariate analysis in addition. ${ }^{9}$ Shen et al. ${ }^{20}$ observed higher incidence of haemorrhage in the presence of pancreatic necrosis. A recent study has found 29.5\% incidence of haemorrhage in the presence of inected necrosis. ${ }^{12}$ In the present study, we observed $29.7 \%$ (14 out of 47) incidence in the presence of infected necrosis. Infected necrosis and presence of sepsis were the risk factors associated with the occurrence of haemorrhage on multivariate analysis.

Incidence of venous thrombosis in the present study was $12.5 \%$, it was not an independent risk factor for bleeding. Others have reported incidence of venous thrombosis ranging from $2-23 \%{ }^{5,11,21}$ Incidence of bleeding was higher amongst those who had a delayed admission to a teritiary care facility. Sharma et al. ${ }^{7}$ also observed similar findings. Haemorrhage is usually a late event in the course of illness. ${ }^{5}$ A recent study by our group has shown poor overall outcome of patients presenting beyond one week of onset of illness. ${ }^{3}$ The management of these patients is challenging due to the presence of peripancreatic inflammatory process, ongoing sepsis, poor physiological status as a result of prolonged illness and inability to exactly localize the source of bleeding. Presence of pseudoaneurysms as localized on angiography is a favorable sit- 
uation as algorithm based directed therapy can be successfully carried out in this situation. ${ }^{13}$ We reported splenic artery to be commonest site for pseudoaneurysm. Others have also observed similar findings. ${ }^{5-7,9,14-16}$ We reported pseudoaneurysms as the cause of haemorrhage in onethird of the cases. Others have reported haemorrhage due to pseudoaneurysms in $10 \%{ }^{11}$ and $18 \%{ }^{7}$ cases. A recent review has reported pseudoaneurysms as the cause of acute haemorrhage in $60 \%$ cases. $^{5}$

However, the exact management of non localized bleed still remains to be elucidated. A recent review has reported $20 \%$ incidence of capillary and venous bleeding. ${ }^{5,6}$ In the present study, bleeding could not be precisely localized in seven $(30 \%)$ of the patients. The cause is usually the slow diffuse venous or capillary oozing which is difficult to pin point. Those with major non localized have very limited surgical options and have a high mortality.

Concluding, the present study has proposed the classification system based on the nature, site, timing and severity of haemorrhage. Based on the classification, we have evolved the management algorithm to plan a treatment strategy.

\section{CONFLICT OF INTEREST}

None.

\section{ORCID}

Vikas Gupta: https://orcid.org/0000-0002-4105-3307

Pradeep Krishna: https://orcid.org/0000-0001-9060-741X

Rakesh Kochhar: https://orcid.org/0000-0002-4077-6474

Asheesh Bhalla: https://orcid.org/0000-0001-5210-1012

Naveen Kalra: https://orcid.org/0000-0002-5030-8682

Jai Dev Wig: https://orcid.org/0000-0002-9430-2426

\section{AUTHOR CONTRIBUTIONS}

Conceptualization: VG, RK, TDY, JDW. Data curation: VG, PK, RK, TDY, AB, NK. Formal analysis: PK. Methodology: VG, RK, TDY, AB, NK. Project administration: VG, RK, TDY, AB. Writing - original draft: VG, PK, RK, TDY. Writing - review \& editing: VG, PK, RK.

\section{REFERENCES}

1. Working Group IAP/APA Acute Pancreatitis Guidelines. IAP/ APA evidence-based guidelines for the management of acute pancreatitis. Pancreatology 2013;13(4 Suppl 2):e1-e15.

2. Manrai M, Kochhar R, Gupta V, Yadav TD, Dhaka N, Kalra $\mathrm{N}$, et al. Outcome of acute pancreatic and peripancreatic collections occurring in patients with acute pancreatitis. Ann Surg 2018;267:357-363.

3. Mallick B, Dhaka N, Sharma V, Malik S, Sinha SK, Dutta U, et al. Impact of timing of presentation of acute pancreatitis to a tertiary care centre on the outcome. Pancreatology 2019;19: 143-148.

4. Banks PA, Bollen TL, Dervenis C, Gooszen HG, Johnson CD, Sarr MG, et al. Classification of acute pancreatitis--2012: revision of the Atlanta classification and definitions by international consensus. Gut 2013;62:102-111.

5. Evans RP, Mourad MM, Pall G, Fisher SG, Bramhall SR. Pancreatitis: preventing catastrophic haemorrhage. World J Gastroenterol 2017;23:5460-5468.

6. Andersson E, Ansari D, Andersson R. Major haemorrhagic complications of acute pancreatitis. Br J Surg 2010;97:1379-1384.

7. Sharma PK, Madan K, Garg PK. Hemorrhage in acute pancreatitis: should gastrointestinal bleeding be considered an organ failure? Pancreas 2008;36:141-145.

8. Flati G, Andrén-Sandberg A, La Pinta M, Porowska B, Carboni M. Potentially fatal bleeding in acute pancreatitis: pathophysiology, prevention, and treatment. Pancreas 2003;26:8-14.

9. Wei AL, Guo Q, Wang MJ, Hu WM, Zhang ZD. Early complications after interventions in patients with acute pancreatitis. World J Gastroenterol 2016;22:2828-2836.

10. Ammori BJ, Madan M, Alexander DJ. Haemorrhagic complications of pancreatitis: presentation, diagnosis and management. Ann R Coll Surg Engl 1998;80:316-325.

11. Balthazar EJ, Fisher LA. Hemorrhagic complications of pancreatitis: radiologic evaluation with emphasis on CT imaging. Pancreatology 2001;1:306-313.

12. Labarca E, Zubia F, Maraví-Poma E, Martinez F; EPAMI Group. Early predictors of abdominal hemorrhage among critically ill patients with pancreatitis: a prospective cohort study. Pancreas 2018;47:1027-1032.

13. Gupta V, Irrinki S, Sakaray YR, Moond V, Yadav TD, Kochhar $\mathrm{R}$, et al. Treatment strategies for bleeding from gastroduodenal artery pseudoaneurysms complicating the course of chronic pancreatitis-a case series of 10 patients. Indian J Gastroenterol 2018;37:457-463.

14. Bergert H, Hinterseher I, Kersting S, Leonhardt J, Bloomenthal A, Saeger HD. Management and outcome of hemorrhage due to arterial pseudoaneurysms in pancreatitis. Surgery 2005;137:323328.

15. Mendelson RM, Anderson J, Marshall M, Ramsay D. Vascular complications of pancreatitis. ANZ J Surg 2005;75:1073-1079.

16. Udd M, Leppäniemi AK, Bidel S, Keto P, Roth WD, Haapiainen RK. Treatment of bleeding pseudoaneurysms in patients with chronic pancreatitis. World J Surg 2007;31:504-510.

17. Balthazar EJ. Complications of acute pancreatitis: clinical and CT evaluation. Radiol Clin North Am 2002;40:1211-1227.

18. Balachandra S, Siriwardena AK. Systematic appraisal of the management of the major vascular complications of pancreatitis. Am J Surg 2005;190:489-495.

19. Tang MY, Chen TW, Bollen TL, Wang YX, Xue HD, Jin ZY, et al. MR imaging of hemorrhage associated with acute pancreatitis. Pancreatology 2018;18:363-369. 
20. Shen X, Sun J, Zhang J, Ke L, Tong Z, Li G, et al. Risk factors and outcome for massive intra-abdominal bleeding among patients with infected necrotizing pancreatitis. Medicine (Baltimore) 2015;94:e1172.
21. Law NM, Freeman ML. Emergency complications of acute and chronic pancreatitis. Gastroenterol Clin North Am 2003;32:11691194, ix. 